Article

\title{
Changes in Spring Phenology in the Three-Rivers Headwater Region from 1999 to 2013
}

\author{
Xianfeng Liu ${ }^{1,2}$, Xiufang Zhu ${ }^{1,2, *}$, Wenquan Zhu ${ }^{1,2}$, Yaozhong Pan ${ }^{1,2}$, Chong Zhang ${ }^{3}$ \\ and Donghai Zhang ${ }^{1,2}$
}

1 State Key Laboratory of Earth Surface Processes and Resource Ecology, Beijing Normal University, Beijing 100875, China; E-Mails: liuxianfeng7987@163.com (X.L.); zhuwq75@bnu.edu.cn (W.Z.); pyz@bnu.edu.cn (Y.P.); donghai_zhang@mail.bnu.edu.cn (D.Z.)

2 College of Resources Science and Technology, Beijing Normal University, Beijing 100875, China

3 College of Tourism and Environment, Shaanxi Normal University, Xi'an 710062, China;

E-Mail: zhangch3348@126.com

* Author to whom correspondence should be addressed; E-Mail: zhuxiufang@bnu.edu.cn; Tel.: +86-10-5880-2932; Fax: +86-10-5880-7656.

Received: 19 March 2014; in revised form: 1 September 2014 / Accepted: 15 September 2014 / Published: 24 September 2014

\begin{abstract}
Vegetation phenology is considered a sensitive indicator of terrestrial ecosystem response to global climate change. We used a satellite-derived normalized difference vegetation index to investigate the spatiotemporal changes in the green-up date over the Three-Rivers Headwater Region (TRHR) from 1999 to 2013 and characterized their driving forces using climatic data sets. A significant advancement trend was observed throughout the entire study area from 1999 to 2013 with a linear tendency of 6.3 days/decade $(p<0.01)$; the largest advancement trend was over the Yellow River source region ( 8.6 days/decade, $p<0.01)$. Spatially, the green-up date increased from the southeast to the northwest, and the green-up date of $87.4 \%$ of pixels fell between the 130th and 150th Julian day. Additionally, about $91.5 \%$ of the study area experienced advancement in the green-up date, of which $80.2 \%$, mainly distributed in areas of vegetation coverage increase, experienced a significant advance. Moreover, it was found that the green-up date and its trend were significantly correlated with altitude. Statistical analyses showed that a $1-{ }^{\circ} \mathrm{C}$ increase in spring temperature would induce an advancement in the green-up date of 4.2 days. We suggest that the advancement of the green-up date in the TRHR might be attributable principally to warmer and wetter springs.
\end{abstract}


Keywords: spring phenology; spatiotemporal change; climate change; Three-Rivers Headwater Region (TRHR); normalized difference vegetation index (NDVI)

\section{Introduction}

Phenology refers to the timing of recurring biological events driven by biotic and abiotic forces [1], which is considered a sensitive indicator of global climate change [2,3]. Conversely, phenology can also regulate climate change through the exchange of terrestrial energy, water and carbon with the atmosphere [4,5]. Phenological records have been used regularly to explore and report the effect of global warming [6-8]. For example, some of the clearest indicators of the biotic response to climate change are the interannual changes in vegetation phenology, especially the advance in the beginning of flowering $[9,10]$. However, changes in phenological processes can have a number of consequential effects, e.g., on biodiversity, agriculture and the economy [10,11]. Therefore, the detection of phenological shift has become an increasingly important topic for research into terrestrial ecosystem and global environmental change [12].

Climate change has demonstrated significant effects on the function and integrity of ecosystems from global to local scales $[10,13]$. Numerous analyses have documented a significant shift in both the green-up date and growth season length in the northern mid- and higher latitude regions [9,14-16]. However, the magnitude and trend of phenological change varies with biomes, location and investigation periods [10,17]. For instance, the average spring advancement across the Northern Hemisphere has been reported as 5.2 days during 1982-1999 and 0.2 days during 2000-2008 [18], whereas the vegetation green-up date has advanced by 6.4 and 7.7 days in Eurasia and North America between 1981 and 1999, respectively [16]. Similarly, the sensitivity of the green-up date to climate change is also exhibited geographically. For example, a 4.1-day advancement was observed on the Tibetan Plateau associated with a $1-^{\circ} \mathrm{C}$ increase in early spring (March to early May) [19], while that observed for temperate vegetation in China was 7.5 days $/{ }^{\circ} \mathrm{C}[20]$. In summary, these findings suggested that improved understanding of the spatiotemporal changes across different scales, locations and investigation periods has significant importance with regard to the accuracy of the evaluation of vegetation productivity and the carbon cycle under an environment of rapid climate change.

The Tibetan Plateau (TP), which is known as the Earth's third pole, has experienced a significant warming trend in past decades [21], and it is regarded as an area most sensitive to climate change [22]. Numerous studies regarding the timing of the green-up date in the TP have been performed using different methods and data sets [19,21,23-26], from which two different conclusions have been drawn. Some scholars believe that the green-up date has presented a significant advance during 1982-2011 [21], whereas others consider there to have been no continuous advance in the green-up date of the TP [19,23-26]. Furthermore, an opposing trend between the southwestern and the other areas of the TP has been detected by Piao et al. [19] and Shen et al. [26], which could possibly be attributed to the non-significant variation of green-up date of the TP. Together, these studies investigated the timing of the green-up date based on the entire TP. It is worth noting that the TP is the highest and largest plateau on Earth (about $257.2 \times 10^{4} \mathrm{~km}^{2}$ ), and significant spatial differentiation in the green-up date 
was found to exist across the TP, highlighting regional differences in climatic conditions. Thus, the conclusiveness of the findings obtained from a single scale is limited. However, comparative multi-scale studies could improve the reliability of the derived conclusions. Unfortunately, few works have focused on the shift in the green-up date in a typical zone of the TP, such as the Three-Rivers Headwaters Region (TRHR). The TRHR, located in the hinterland of the Qinghai TP, is very sensitive to climate change. Additionally, as an important national zone of ecological function, the TRHR has attracted significant attention regarding the evaluation of its ecological environmental response to global climate change. The shift of phenology has undoubtedly become a core issue in research into global climate change.

In order to explore the variability of the green-up date in a typical ecological zone of the TP under rapid climate change, this paper aims to investigate the spatiotemporal pattern and the change of meadow in the green-up date over the TRHR from 1999 to 2013 and its relation to climatic factors. More specifically, we primarily investigate the following three points: (1) the temporal and spatial variability of the green-up date in the TRHR; (2) the characteristics of the green-up date along altitudinal gradients; and (3) the possible factors that influence phenological shift. Greater knowledge regarding the relationship between phenology and climate on differing scales could help us better understand the mechanisms of vegetation response to climate change.

\section{Materials and Methods}

\subsection{Study Area}

The TRHR, which is located in the hinterland of the TP, is the source area of the Yangtze, Yellow and Lancang rivers (Figure 1). The TRHR is known as the "Chinese water tower" [22], because of its high average altitude of more than $4000 \mathrm{~m}$ [27]. The annual mean temperature in the TRHR is lower than $10{ }^{\circ} \mathrm{C}$, and a decreasing trend of precipitation exists from the southeast to the northwest. The main vegetation type is grassland, including meadow and steppe, of which meadow is distributed over most parts of the entire area. Therefore, we selected meadow as the target vegetation type for our research.

Figure 1. Study area and the distribution of meteorological stations.

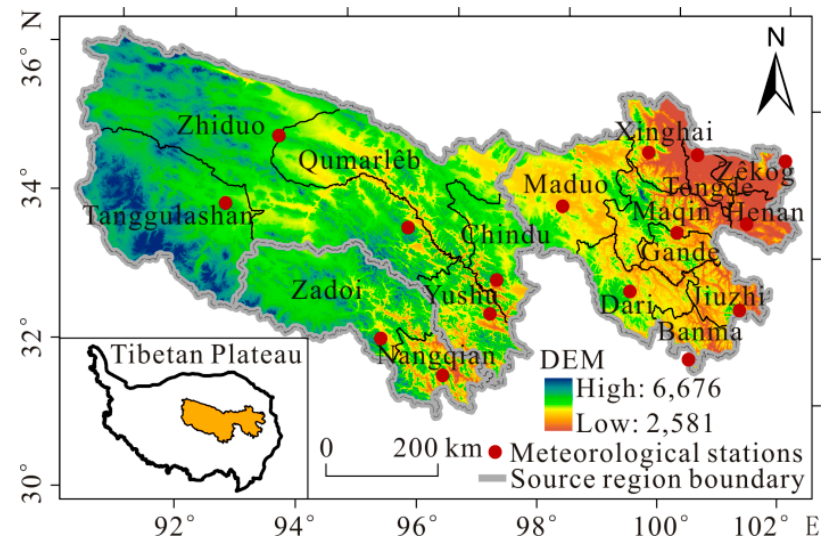

\subsection{Data Sets}

The normalized difference vegetation index (NDVI), which is defined as the ratio of the difference between near-infrared reflectance and red visible reflectance to their sum, is an effective indicator of 
vegetation greenness [28]. Our study adopted the SPOT-VGT NDVI time series from 1999 to 2013, collected from the Flemish Institute for Technological Research of Belgium (http://free.vgt.vito.be/). The spatial resolution of the NDVI data sets is $1 \times 1 \mathrm{~km}^{2}$ using the 10-day maximum value composition method. We obtained the vector boundary of the meadow from a 1:1,000,000 map of vegetation in China [29].

The meteorological data sets, recorded at 16 meteorological stations in the TRHR during 1998-2013, comprised monthly mean temperature and monthly cumulative precipitation derived from the China Meteorological Data Sharing Service System (http://cdc.cma.gov.cn). The digital elevation model (DEM) data with 90-m resolution were collected from the SRTM3 data, which were measured by the National Aeronautics and Space Administration and the Department of Defense National Mapping Bureau.

\subsection{Method}

\subsubsection{NDVI Time Series Reconstruction}

NDVI time series data are used widely to investigate phenological shift. However, many efforts to monitor changes in vegetation phenology by NDVI time series data are often hindered by the low quality of the original data sets due to various factors, e.g., cloud contamination and atmospheric variability [30]. Thus, it is necessary to implement a smoothing process and to construct new NDVI time series data sets. The method of the harmonic analysis of time series (HANTS) algorithm for NDVI time series reconstruction $[31,32]$ fully considers the plant growth cycle and the dual characteristics of the data. Thus, we adopted the HANTS method to remove both noise and invalid data.

\subsubsection{Phenological Metrics Extraction}

Currently, many methods for extracting phenological metrics from NDVI time series data have been proposed [16,20,33-37]; however, a universally accepted method for the extraction of phenological metrics does not exist [38]. The method proposed by Piao [20] integrates the fixed threshold value method with the biggest change rate method, the extraction result of which is close to the average of extraction results by multi-methods [26]. Therefore, the green-up date in our study was retrieved using the threshold value of NDVI, which is determined through the maximum rate of change in the multiyear average annual seasonal NDVI curve from January to September, smoothed by the HANTS method [19,20]. Details of this approach are as follows: (1) we first calculated the multiyear average NDVI time series curve from 1999 to 2013 and acquired the ratio of NDVI change using the following formula, $N D V I_{\text {ratio }}=\left(N D V I_{t+1}-N D V I_{t}\right) / N D V I_{t}$, where $t$ is time; (2) we then obtained the NDVI value at the date of maximum $N D V I_{\text {ratio }}$ as the threshold NDVI to determine the green-up date; and (3) finally, we identified the green-up date by integrating the threshold NDVI and the fitted NDVI time series curve using sixth polynomial fitting for each year. In order to exclude the interference of environmental factors during the non-growing season, we added the restriction that the green-up date must fall between the dates of the left minimum of the NDVI and the maximum of the NDVI. 


\subsubsection{Analysis}

The spatiotemporal trend of the green-up date in the TRHR from 1999 to 2013 was characterized by slope, which was calculated by the linear regression line fitted to the interannual variation of the green-up date [39]. The statistical significance of the trend of the green-up date was assessed based on significance tests. The formula of the slope is as follows:

$$
\text { Slope }=\frac{n \times \sum_{i=1}^{n}\left(i \times D^{\prime} Y_{i}\right)-\sum_{i=1}^{n} i \sum_{i=1}^{n} D O Y_{i}}{n \times \sum_{i=1}^{n} i^{2}-\left(\sum_{i=1}^{n} i\right)^{2}}
$$

where Slope is the trend of the green-up date, $n$ is equal to $15, i$ is the order of the year from 1 to 15 in the study period and $D O Y_{i}$ is the green-up date in the $i$-th year. When Slope $>0$, DOY shows an increasing trend, and when Slope $<0$, DOY shows a decreasing trend.

In order to analyze the altitudinal gradient characteristics of the green-up date, we reclassified the DEM data by $100-\mathrm{m}$ intervals and then extracted the mean green-up date of each vertical gradient zone from 1999 to 2013.

To identify the driving forces behind the change in the green-up date, site-by-site correlation analysis between green-up dates and climatic factors was employed in our study. Specifically, we extracted the green-up date for an area with a boundary of $3 \times 3 \mathrm{~km}^{2}$ based on the meteorological stations and then calculated the Pearson correlation coefficient between the green-up date and meteorological data.

\section{Results}

\subsection{Validation}

Satellite-derived data require in situ observations to determine their reliability and accuracy. Thus, we compared the green-up dates retrieved by satellite, against ground-observed phenological data from three agro-meteorological stations (Qumarlêb station, Henan station and Gande station) in the TRHR during 2000-2010 (not shown). The mean absolute error between the retrieved and observed green-up dates was 10.9 days, and the root mean square error was 13.2 days. The results showed relatively high consistency between the field-observed data and remotely sensed retrieval results, indicating that the retrieved green-up dates from the NDVI time series data have reasonably high accuracy considering the temporal resolution of the NDVI data set.

\subsection{Temporal Variation in Vegetation Phenology}

Figure 2 illustrates the interannual change in vegetation green-up dates during 1999-2013 over the TRHR. A significant advancement trend can be observed with a linear tendency of 6.3 days/decade $\left(R^{2}=0.41, p<0.01\right)$ (Figure 2a). Meanwhile, Figure $2 \mathrm{~b}$ shows the interannual variations of the green-up dates for the three different river source regions. The largest advancement trend can be observed in the Yellow River source region with a linear tendency of 8.6 days/decade $\left(R^{2}=0.62\right.$, $p<0.01)$, whereas the Lancang River source region presents only a slight advancement in the spring green-up date (slope: 2.9 days/decade, $R^{2}=0.10, p=0.26$ ). 
Figure 2. (a) Interannual change in the vegetation green-up date for the entire study area and (b) for individual river sources during 1999-2013.
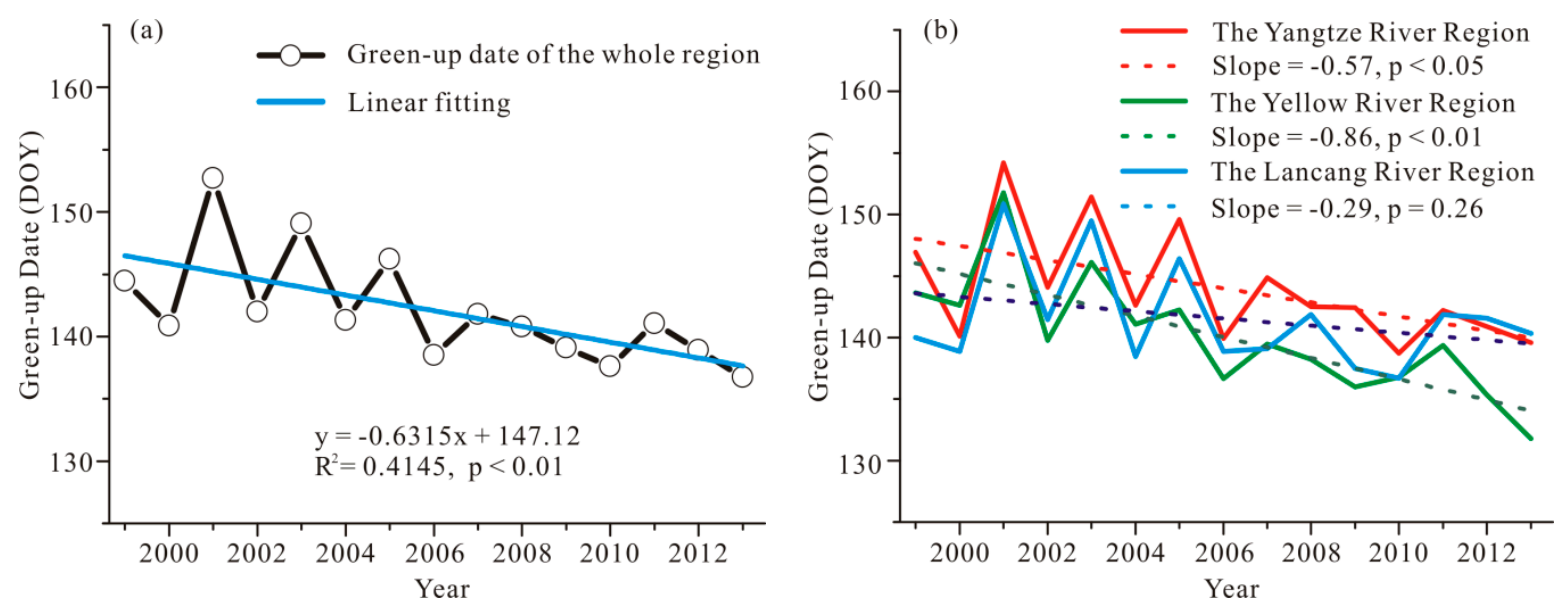

The spatial pattern of the temporal change in the vegetation green-up date is shown in Figure 3 . Over $91.5 \%$ of the entire meadow area experienced advancement in the green-up date (Figure 3a), of which 80.2\% demonstrated significant advancement at the $p<0.05$ level from 1999 to 2013; particularly in the Yellow River source region and the northwest of Qumarlêb county (Figure 3b). The histogram of the trend in green-up dates illustrates an advancement of $0-10$ days/decade for $71.8 \%$ of the entire area.

Figure 3. (a) The spatial pattern of the trend in the vegetation green-up date and (b) the significance level of the trend during 1999-2013 in the TRHR.
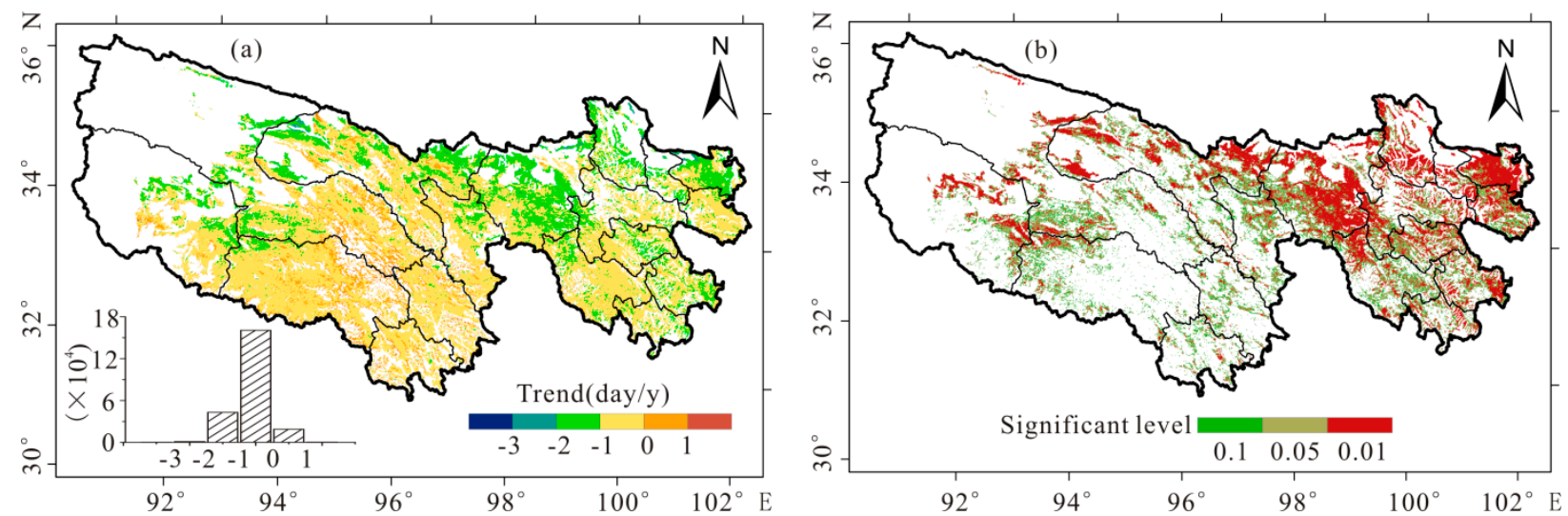

\subsection{Spatial Variation in Vegetation Phenology}

The spatial pattern of the vegetation green-up date is shown in Figure 4. The green-up date presents an increasing trend from the southeast to the northwest, which corresponds to the spatial difference in climate. The green-up date mainly occurred at the 120th-140th Julian day in the east and the middle of the study area, and at around the 140th to 160th Julian day in the northwest. The frequency distribution of the green-up dates over the TRHR shows that $87.4 \%$ of the pixel green-up dates occur between the 130th and 150th Julian days. 
Figure 4. Spatial pattern of the averaged vegetation green-up dates during 1999-2013 in the TRHR.

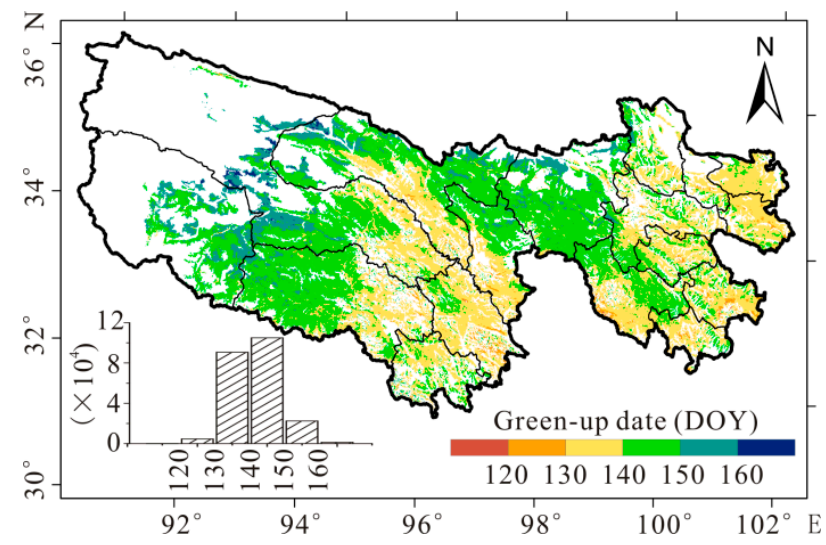

\subsection{Altitude Gradient vs. Spring Phenology}

We further examined the variation of the green-up date and its trend with the altitudinal gradient (Figure 5). Figure 5a presents the variation in the green-up date with altitude, which exhibits a trend of delay in the green-up date with increasing altitude across the study area with a linear tendency of 0.31 days $/ 100 \mathrm{~m}\left(R^{2}=0.54, p<0.01\right)$. Two distinctly differing trends are separated by an altitude of $3700 \mathrm{~m}$. The green-up date is earlier in areas with lower altitude (slope $=-0.77, R^{2}=0.63, p<0.01$, below $3700 \mathrm{~m}$ ), which corresponds to the results shown in Figure 3. However, the green-up date increases continuously with increasing altitude (slope $=0.57, R^{2}=0.90, p<0.01$ ) above $3700 \mathrm{~m}$, because of the lower temperatures at higher altitudes, which is in accord with earlier findings [40]. Furthermore, the trend of the vegetation green-up date presents an advancement trend in all altitude zones, and the advancement trend of the green-up date in areas of lower altitude is higher than that in areas of higher altitude (Figure $5 b$ ).

Figure 5. Altitudinal gradient in the green-up date and its trend over the TRHR (the error bar denotes the standard deviation of the green-up date).
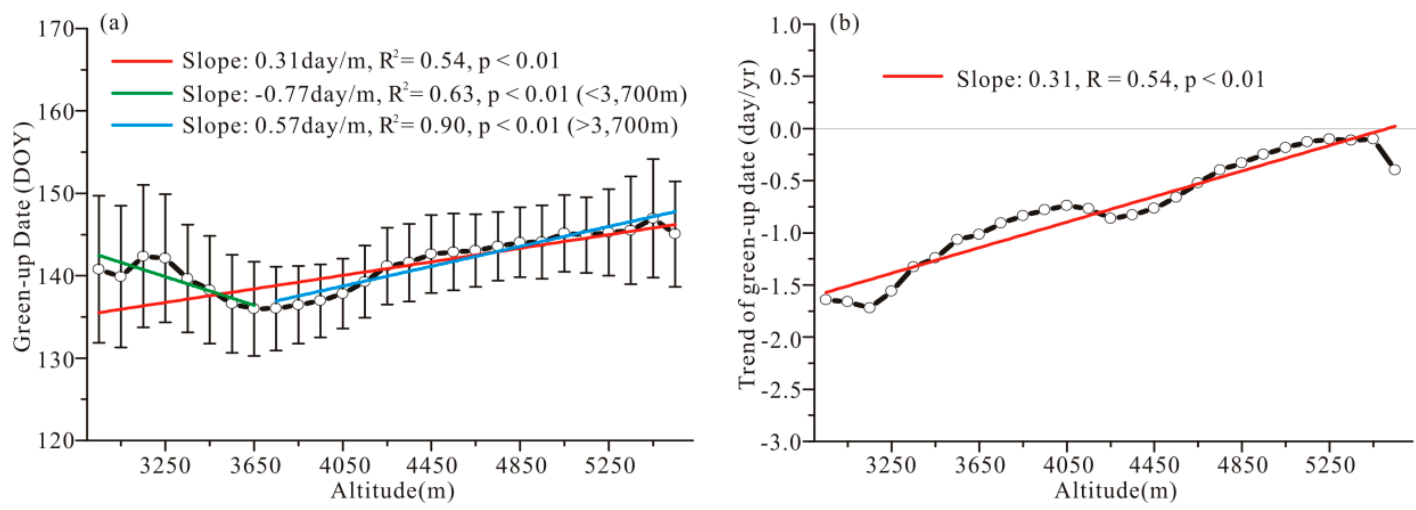

\subsection{Climatic Drivers for Spring Phenological Shift}

The hydrothermal condition has been widely recognized as a key forcing factor in vegetation growth. In our study, the regional average green-up date showed a significant advancement trend during the recent 15 years, corresponding to a slight increase both in spring (March-May) and winter 
(December-February) temperature and a significant increase in precipitation in spring (see the inset in Figure 6). Moreover, $87.5 \%$ of all stations presented an increasing trend in spring and winter temperature. We found that the correlation coefficient between climatic factors (including mean temperature and cumulative precipitation) and the green-up date in spring is stronger than in winter at most of the available meteorological stations (Table 1). This phenomenon indicates that warmer springs are likely the principal forces driving green-up date advancement in the TRHR during the study period. Furthermore, most of the available meteorological stations presented a significant negative correlation between the green-up date and spring temperature, while statistical analyses showed a slight correlation between the green-up date and spring precipitation, winter temperature and winter precipitation, except for spring precipitation, in Guinan County. This seems contrary to the fact that no significant increase was found in spring temperature during 1999-2013, despite the significant advancement in the green-up date. This might be related to the timing of the study period, because a strong cold surge occurred in Qinghai in 2011 during winter and spring, which induced extremely low temperatures that changed the trend. As shown in the inset of Figure 6a, the first year and the last three years (1999, 2011-2013) in the time series exert considerable influence on the trend of spring temperature. Hence, we excluded these years and performed further analysis on the trend of climate factors from 2000 to 2010. This time, we found that a significant increasing trend was exhibited both in spring and in winter temperature during 2000-2010 (slope $=0.173{ }^{\circ} \mathrm{C} / \mathrm{y}, p<0.01$ for spring; slope $=0.127{ }^{\circ} \mathrm{C} / \mathrm{y}, p<0.01$ for winter). Meanwhile, almost all of the available meteorological stations showed a significant increase at the $p<0.05$ level (not shown), which confirms that warmer springs are likely the principal forces driving green-up date advancement. In addition, statistical analyses show that an increase of $1^{\circ} \mathrm{C}$ in spring temperatures would induce an advancement in the green-up date of 4.2 days.

Table 1. Correlation coefficients (CC) between the green-up date and climatic factors.

\begin{tabular}{cccccccc}
\hline \multirow{2}{*}{ Station } & \multirow{2}{*}{ Name } & \multirow{2}{*}{ Altitude $(\mathbf{m})$} & \multicolumn{3}{c}{$\mathbf{C C}$} & \multicolumn{2}{c}{ Sensitivity to $\mathbf{T}_{\mathbf{s}}$} \\
\cline { 3 - 6 } & & & $\mathbf{T}_{\mathbf{s}}$ & $\mathbf{T}_{\mathbf{w}}$ & $\mathbf{P}_{\mathbf{s}}$ & $\mathbf{P}_{\mathbf{w}}$ & -6.3 \\
52974 & Tongren & 2491 & $-0.71 * *$ & -0.07 & -0.23 & -0.34 & -1.5 \\
52955 & Guinan & 3120 & -0.16 & 0.10 & $-0.62 * *$ & -0.08 & -1.3 \\
52943 & Xinghai & 3323 & -0.16 & -0.01 & -0.31 & 0.11 & -4.0 \\
56065 & Henan & 3500 & $-0.56 * *$ & -0.30 & -0.38 & -0.25 & -8.3 \\
56151 & Banma & 3530 & $-0.68 * *$ & -0.27 & 0.05 & -0.03 & -11.4 \\
56067 & Jiuzhi & 3629 & $-0.66 * *$ & -0.01 & 0.12 & 0.28 & -6.6 \\
56125 & Nangqian & 3644 & $-0.73 * *$ & -0.40 & 0.14 & 0.07 & -1.2 \\
56029 & Yushu & 3681 & -0.21 & -0.24 & -0.04 & 0.33 & -5.3 \\
56043 & Guoluo & 3719 & $-0.57 * *$ & -0.31 & -0.10 & 0.06 & -3.7 \\
56046 & Dari & 3968 & $-0.53 * *$ & -0.49 & -0.46 & -0.37 & -4.3 \\
56018 & Zaduo & 4066 & $-0.75 * *$ & -0.09 & 0.44 & 0.26 & -1.1 \\
56021 & Qumarlêb & 4175 & -0.15 & 0.47 & 0.26 & -0.09 & -0.4 \\
56033 & Maduo & 4272 & -0.04 & -0.15 & -0.02 & -0.02 & -2.0 \\
56034 & Qingshuihe & 4415 & -0.28 & -0.27 & 0.00 & -0.24 & -0.7 \\
56004 & Tuotuohe & 4533 & -0.10 & 0.11 & -0.23 & -0.19 & -5.1 \\
52908 & Wudaoliang & 4612 & $-0.51 * *$ & -0.36 & -0.38 & -0.08 & \\
\hline
\end{tabular}

Notes: ** Indicates significance at the $p<0.05$ level. $\mathrm{T}_{\mathrm{s}}$ denotes the mean temperature of spring (March, April and May). $\mathrm{T}_{\mathrm{W}}$ denotes the mean temperature of winter (December, January and February). $\mathrm{P}_{\mathrm{s}}$ denotes the cumulative precipitation of spring (March, April and May). $\mathrm{P}_{\mathrm{w}}$ denotes the cumulative precipitation of winter (December, January and February). Sensitivity to $T_{\mathrm{s}}$ indicates advanced days for a $1-{ }^{\circ} \mathrm{C}$ increase in spring temperatures. 
Figure 6. Trend of climatic factors: (a) spring temperature; (b) spring precipitation; (c) winter temperature; and (d) winter precipitation. The inset plot indicates the spatially averaged variation of climate factors ((a) slope $=0.048{ }^{\circ} \mathrm{C} / \mathrm{y}, \quad p=0.24$; (b) slope $=1.97 \mathrm{~mm} / \mathrm{y}, p=0.01$; (c) slope $=0.07{ }^{\circ} \mathrm{C} / \mathrm{y}, p=0.28$; (d) slope $=0.18 \mathrm{~mm} / \mathrm{y}$, $p=0.55)$. The black circles indicate sites with a significant trend $(p<0.05)$.
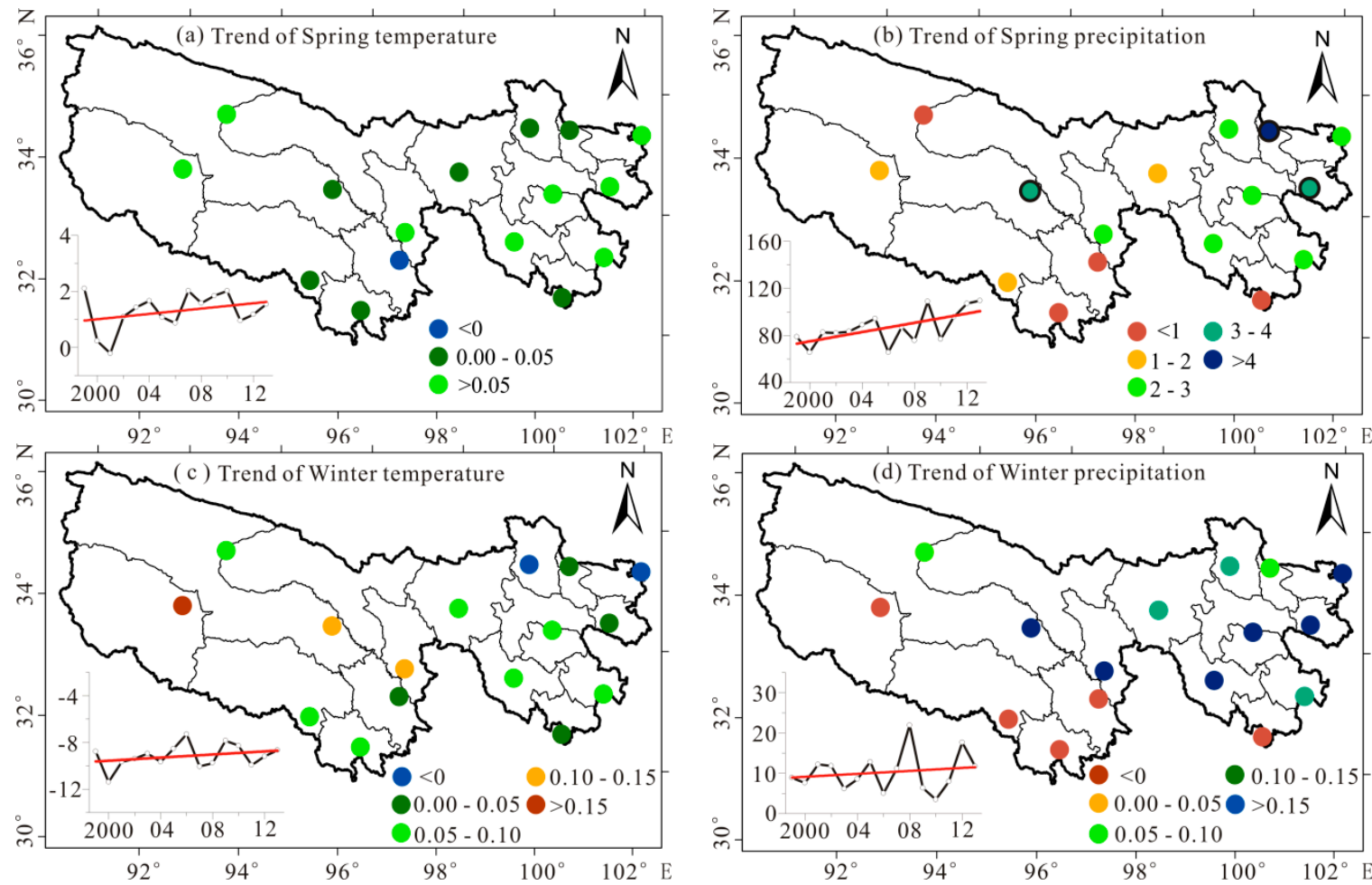

Meanwhile, we also found that the precipitation in the south of the TRHR presented a decreasing trend in winter and a weak increase in spring, corresponding to a slight advancement in the green-up date in most areas (Figure 3a), especially the Lancang River source region. This phenomenon indicates that the green-up date might also be related to spring precipitation. Therefore, the variability of the green-up date might be forced by multiple climatic factors; any single climate factor is incapable of fully explaining the variation of the green-up date.

\section{Discussion}

\subsection{Comparison with Previous Studies}

Phenological changes of the TP have been discussed by many scholars; however, there is still no generally accepted conclusion about the trend of spring phenology. One reason for this might be that the conclusions have been drawn from different studies conducted using different data sets, methods and study periods $[19,26-29,41]$. We argue that the average trend of the entire TP cannot characterize the real trend of spring phenology, because of the differences in the trend between the southwest and the parts of the TP [29]. Our study indicates a significant advancement in the TRHR, which partly confirms the existence of a reversed trend in spring phenology on the TP. Therefore, to understand fully the changes in vegetation phenology, it is necessary to strengthen the study of subregions of the TP under the environment of rapid climate change. 
It is worth noting that the phenological shift was not only related to the increase in temperature and precipitation, but also related to other climatic (e.g., solar radiation, photoperiod length, $\mathrm{CO}_{2}$ concentration) [42] and anthropogenic factors. Generally, land use/cover change is regarded as an important forcing factor in vegetation growth [22]. Previous studies have shown that the trend in NDVI values in the TRHR is divided across the $34^{\circ} \mathrm{N}$ line of latitude. An increasing trend has been detected to the north of this line, especially in the Yellow River region, whereas a decreasing trend has been found to the south, especially in the Lancang River region [43]. Based on our results, shown in Figure 3, we can conclude that those regions experiencing significant advancement in spring phenology are distributed mainly in areas of vegetation coverage increase, and vice versa.

Elevation plays an important role in the redistribution of temperature and precipitation, and we found a strong dependence on altitude in the green-up date and its trend. Nagai et al. [44] also found that the timing of the green-up date was correlated to vertical gradient and that the sensitivity of the timing of the green-up date to air temperature was also dependent on altitude. Unfortunately, in our study, the relationship between the green-up date and air temperature, together with the sensitivity of the green-up date to spring temperature, did not exhibit a consistent trend with vertical gradient (Table 1). This might be related to the difference in horizon zone, and there are many uncertainties due to the complexity of the underlying surface across the TRHR. Thus, additional studies along the vertical gradient for a homogeneous horizon zone would help us understand better the relationship between the sensitivity of the green-up date and climate and altitudinal gradient.

\subsection{Uncertainties}

Without a doubt, uncertainties induced by the different methods used in the estimation of the green-up date from remote sensing data contribute to the differences found in the published results $[41,45]$. In our study, the commonly used and robust method proposed by Piao [20] was adopted in order to reduce this uncertainty [26]. Furthermore, the uncertainties are also correlated with the data sets. Previous studies have documented the differences in spring phenology derived from AVHRR NDVI, SPOT-VGT NDVI and MODIS NDVI data sets [46]. Moreover, the differences between data sets were considered larger than among the various methods [26]. In order to improve the reliability of the retrieved results, the data set in our study was processed based on phenoregion, which was used to exclude areas of non-vegetation and to reduce high-frequency noise existing in the retrieved phenological metrics [33]. In the analysis of the driving forces, we only analyzed the correlation between the green-up date and climatic factors; however, the internal mechanisms of vegetation phenology generally depend on the response of plant physiological processes to climate change. Thus, the internal mechanisms should be investigated further with emphasis on the physiological characteristics of the plants. It should be noted that although significant improvements have been made regarding the use of SPOT-VGT NDVI and MODIS NDVI data for monitoring land photosynthetic capacity [46], the AVHRR NDVI is still an irreplaceable data set with regard to the assessment of long-term land surface information. Thus, a long-term NDVI data set that combines the current three main NDVI data sets (AVHRR, SPOT and MODIS) has great significance with regard to better understanding of the shift of phenological metrics.

A comprehensive comparison and assessment of the field-observed data indicated that our estimation of the green-up date, based on remotely sensed data, is later than the observed data; however, the 
trends of change in green-up dates are consistent. On the one hand, this might be because the spectral information during the onset of green-up is weak; thus, the sensor cannot capture the initial information on vegetation. On the other hand, this might be related to the temporal and spatial resolution of the data set. It should be noted that meadow consists of many plants, i.e., Kobresia pygmaea alpine meadow [29]. Some of the plants unfold their leaves earlier than retrieved by the remotely sensed data, which is usually recorded as the observed green-up date. In addition, heterogeneity in vegetation cover might contribute to discrepancies in the retrieved green-up dates [47]. Generally, green-up dates tend to be earlier under high vegetation cover than low vegetation cover. Compared with our previous study [43], we argue that the retrieved green-up date is also subject to influence from changes in vegetation cover. Nevertheless, the method based on remote sensing remains valid. In order to characterize phenological shifts more accurately, information that is more detailed is required to develop the understanding of the differences between the methods of remote sensing and field observation. To further this process, larger sets of observational data are needed.

\subsection{Potential Implications of Phenological Shift}

Terrestrial ecosystem carbon cycling is related significantly to vegetation phenological shifts [15]. The prolongation of the growing season of the TP, especially the advancement of spring green-up, is considered one of the principal factors that enhances the carbon sink [48]. As an important national ecological zone, the TRHR has important ecological significance for China in providing water resources, balancing greenhouse gases and regulating climate. Recently, climate change in the TRHR has changed its phenological metrics and function as a carbon sink; however, the definitive effect of change in growing season length on the carbon balance is still not clear. Furthermore, phenological shifts could also affect animal husbandry production in the TRHR, which eventually could alter local livestock management and economic development.

In addition, the frequency and extent of extreme events have been increasing under rapid climate change. These extreme events, such as drought, cold surges and heat waves, influence vegetation growth and could eventually induce a shift of vegetation phenology [49]. Thus, the impact of extreme events on vegetation phenology should be considered in future work.

\section{Conclusions}

A satellite-derived NDVI was combined with climatic factors to explore the spatiotemporal pattern of vegetation phenological shift and its driving forces. Our results indicate a significant trend of advancement throughout the entire study area from 1999 to 2013 with a linear tendency of 6.3 days/decade $(p<0.01)$; the largest trend was in the Yellow River source region $(8.6$ days/decade, $p<0.01$ ). Spatially, the green-up date increased from the southeast to the northwest. About $91.5 \%$ of the entire area has experienced advancement of the green-up date, of which $80.2 \%$, mainly distributed in areas of vegetation coverage increase, experienced a significant advance. Moreover, the green-up date and its trend were significantly correlated with altitude gradient. Statistical analyses showed that an increase of $1{ }^{\circ} \mathrm{C}$ in spring temperature would induce an advancement in the green-up date of 4.2 days. We have argued that the advancement of the green-up date in the TRHR might be attributable primarily to warmer and wetter springs. 


\section{Acknowledgments}

This work was supported by the Major Project of High Resolution Earth Observation System, China. We thank the editor and the three anonymous reviewers for their valuable and constructive comments, which have helped us to improve the manuscript.

\section{Author Contributions}

Xianfeng Liu and Xiufang Zhu designed the research; Xianfeng Liu performed the research; Xianfeng Liu, Xiufang Zhu, Wenquan Zhu, Yaozhong Pan, Chong Zhang and Donghai Zhang analyzed the data; Xianfeng Liu, Xiufang Zhu and Wenquan Zhu wrote the paper.

\section{Conflicts of Interest}

The authors declare no conflict of interest.

\section{References}

1. Lieth, H. Purposes of a phenology book. In Phenology and Seasonality Modeling; Springer: Berlin, Germany, 1974; pp. 3-19.

2. Menzel, A.; Fabian, P. Growing season extended in Europe. Nature 1999, 397, doi:10.1038/17709.

3. Schwartz, M.D. Green-wave phenology. Nature 1998, 394, 839-840.

4. Peñuelas, J.; Rutishauser, T.; Filella, I. Phenology feedbacks on climate change. Science 2009, 324, 887-888.

5. Piao, S.; Ciais, P.; Friedlingstein, P.; Peylin, P.; Reichstein, M.; Luyssaert, S.; Margolis, H.; Fang, J.; Barr, A.; Chen, A.; et al. Net carbon dioxide losses of northern ecosystems in response to autumn warming. Nature 2008, 451, 49-52.

6. Menzel, A.; Sparks, T.H.; Estrella, N.; Koch, E.; Aasa, A.; Ahas, R.; Alm-Kübler, K.; Bissolli, P.; Braslavská, O.G.; Briede, A.; et al. European phenological response to climate change matches the warming pattern. Glob. Chang. Biol. 2006, 12, 1969-1976.

7. Parry, M.L., Canziani, O.F., Palutikof, J.P., van der Linden, P.J., Hanson, C.E., Eds. Climate Change 2007: Impacts, Adaptation and Vulnerability: Contribution of Working Group II to the Fourth Assessment Report of the Intergovernmental Panel on Climate Change; Cambridge University Press: Cambridge, UK, 2007; Volume 4.

8. Rosenzweig, C.; Karoly, D.; Vicarelli, M.; Neofotis, P.; Wu, Q.; Casassa, G.; Menzel, A.; Root, T.L.; Estrella, N.; Seguin, B.; et al. Attributing physical and biological impacts to anthropogenic climate change. Nature 2008, 453, 353-357.

9. Menzel, A.; Sparks, T.; Estrella, N.; Roy, D. Altered geographic and temporal variability in phenology in response to climate change. Glob. Ecol. Biogeogr. 2006, 15, 498-504.

10. Walther, G.R.; Post, E.; Convey, P.; Menzel, A.; Parmesan, C.; Beebee, T.J.; Fromentin, J.M.; Hoegh-Guldberg, O.; Bairlein, F. Ecological responses to recent climate change. Nature 2002, 416, 389-395. 
11. Thuiller, W.; Albert, C.; Araújo, M.B.; Berry, P.M.; Cabeza, M.; Guisan, A.; Hickler, T.; Midgley, G.F.; Paterson, J.; Schurr, F.M.; et al. Predicting global change impacts on plant species' distributions: Future challenges. Perspect. Plant Ecol. 2008, 9, 137-152.

12. Schwartz, M.D. Advancing to full bloom: Planning phenological research for the 21 st century. Int. J. Biometeorol. 1999, 42, 113-118.

13. Parmesan, C. Ecological and evolutionary responses to recent climate change. Ann. Rev. Ecol. Evol. Syst. 2006, 37, 637-669.

14. Penuelas, J.; Filella, I.; Comas, P. Changed plant and animal life cycles from 1952 to 2000 in the Mediterranean region. Glob. Chang. Biol. 2002, 8, 531-544.

15. Piao, S.; Friedlingstein, P.; Ciais, P.; Viovy, N.; Demarty, J. Growing season extension and its impact on terrestrial carbon cycle in the Northern Hemisphere over the past 2 decades. Glob. Biogeochem. Cycle 2007, 21, GB3018, doi:10.1029/2006gb002888.

16. Zhou, L.; Tucker, C.J.; Kaufmann, R.K.; Slayback, D.; Shabanov, N.V.; Myneni, R.B. Variations in northern vegetation activity inferred from satellite data of vegetation index during 1981 to 1999. J. Geophys. Res.: Atmos. (1984-2012) 2001, 106, 20069-20083.

17. Linderholm, H.W. Growing season changes in the last century. Agric. For. Meteorol. 2006, 137, 1-14.

18. Parmesan, C. Influences of species, latitudes and methodologies on estimates of phenological response to global warming. Glob. Chang. Biol. 2007, 13, 1860-1872.

19. Piao, S.; Cui, M.; Chen, A.; Wang, X.; Ciais, P.; Liu, J.; Tang, Y. Altitude and temperature dependence of change in the spring vegetation green-up date from 1982 to 2006 in the Qinghai-Xizang Plateau. Agric. For. Meteorol. 2011, 151, 1599-1608.

20. Piao, S.; Fang, J.; Zhou, L.; Ciais, P.; Zhu, B. Variations in satellite-derived phenology in China's temperate vegetation. Glob. Chang. Biol. 2006, 12, 672-685.

21. Zhang, G.; Zhang, Y.; Dong, J.; Xiao, X. Green-up dates in the Tibetan Plateau have continuously advanced from 1982 to 2011. Proc. Natl. Acad. Sci. USA 2013, 110, 4309-4314.

22. Liu, J.; Xu, X.; Shao, Q. The spatial and temporal characteristics of grassland degradation in the three-river headwaters region in Qinghai Province. J. Geogr. Sci.. 2008, 18, 259-273.

23. Yu, H.; Luedeling, E.; Xu, J. Winter and spring warming result in delayed spring phenology on the Tibetan Plateau. Proc. Natl. Acad. Sci. USA 2010, 107, 22151-22156.

24. Shen, M.; Sun, Z.; Wang, S.; Zhang, G.; Kong, W.; Chen, A.; Piao, S. No evidence of continuously advanced green-up dates in the Tibetan Plateau over the last decade. Proc. Natl. Acad. Sci. USA 2013, 110, E2329.

25. Wang, T.; Peng, S.; Lin, X.; Chang, J. Declining snow cover may affect spring phenological trend on the Tibetan Plateau. Proc. Natl. Acad. Sci. USA 2013, 110, E2854-E2855.

26. Shen, M.; Zhang, G.; Cong, N.; Wang, S.; Kong, W.; Piao, S. Increasing altitudinal gradient of spring vegetation phenology during the last decade on the Qinghai-Tibetan Plateau. Agric. For. Meteorol. 2014, 189, 71-80.

27. Zheng, D. The system of physico-geographical regions of the Qinghai-Xizang (Tibet) Plateau. Sci. China Ser. D 1996, 26, 410-417.

28. Myneni, R.B.; Keeling, C.; Tucker, C.; Asrar, G.; Nemani, R. Increased plant growth in the northern high latitudes from 1981 to 1991. Nature 1997, 386, 698-702. 
29. Hou, X.; Chinese Academy of Science, The Editorial Board of Vegetation Map of China; Vegetation Atlas of China; Scientific Press: Beijing, China, 2001. (In Chinese)

30. Zhu, W.; Pan, Y.; He, H.; Wang, L.; Mou, M.; Liu, J. A changing-weight filter method for reconstructing a high-quality NDVI time series to preserve the integrity of vegetation phenology. IEEE Trans. Geosci. Remote Sens. 2012, 50, 1085-1094.

31. Jakubauskas, M.E.; Legates, D.R.; Kastens, J.H. Harmonic analysis of time-series AVHRR NDVI data. Photogramm. Eng. Remote Sen. 2001, 67, 461-470.

32. Roerink, G.; Menenti, M.; Verhoef, W. Reconstructing cloudfree NDVI composites using fourier analysis of time series. Int. J. Remote Sens. 2000, 21, 1911-1917.

33. Julien, Y; Sobrino, J. Global land surface phenology trends from gimms database. Int. J. Remote Sens. 2009, 30, 3495-3513.

34. Lloyd, D. A phenological classification of terrestrial vegetation cover using shortwave vegetation index imagery. Remote Sens. 1990, 11, 2269-2279.

35. Reed, B.C.; Brown, J.F.; VanderZee, D.; Loveland, T.R.; Merchant, J.W.; Ohlen, D.O. Measuring phenological variability from satellite imagery. J. Veg. Sci. 1994, 5, 703-714.

36. Yu, F.; Price, K.P.; Ellis, J.; Shi, P. Response of seasonal vegetation development to climatic variations in eastern central Asia. Remote Sens. Environ. 2003, 87, 42-54.

37. Stöckli, R.; Vidale, P.L. European plant phenology and climate as seen in a 20 -year AVHRR land-surface parameter dataset. Int. J. Remote Sens. 2004, 25, 3303-3330.

38. White, M.; de Beurs, K.; Didan, K.; Inouye, D.; Richardson, A.; Jensen, O.; O’Keefe, J.; Zhang, G.; Nemani, R.; van Leeuwen, W.; et al. Intercomparison, interpretation, and assessment of spring phenology in north America estimated from remote sensing for 1982-2006. Glob. Chang. Biol. 2009, 15, 2335-2359.

39. Stow, D.; Daeschner, S.; Hope, A.; Douglas, D.; Petersen, A.; Myneni, R.; Zhou, L.; Oechel, W. Variability of the seasonally integrated normalized difference vegetation index across the north slope of Alaska in the 1990s. Int. J. Remote Sens. 2003, 24, 1111-1117.

40. Cayan, D.R.; Dettinger, M.D.; Kammerdiener, S.A.; Caprio, J.M.; Peterson, D.H. Changes in the onset of spring in the western United States. Bull. Am. Meteorol. Soc. 2001, 82, 399-415.

41. Ding, M.; Zhang, Y.; Liu, L.; Wang, Z. Spatiotemporal changes of commencement of vegetation re-greening and its response to climate change on Tibetan Plateau. Adv. Clim. Chang. Res. 2011, 7, 317-323. (In Chinese)

42. Wu, X.; Liu, H. Consistent shifts in spring vegetation green-up date across temperate biomes in China, 1982-2006. Glob. Chang. Biol. 2013, 19, 870-880.

43. Liu, X.; Zhang, J.; Zhu, X.; Pan, Y.; Liu, Y.; Zhang, D.; Lin, Z. Spatiotemporal changes in vegetation coverage and its driving factors in the Three-River Headwaters Region during 2000-2011. J. Geogr. Sci. 2014, 24, 288-302.

44. Nagai, S.; Saitoh, T.M.; Nasahara, K.N.; Suzuki, R. Spatio-temporal distribution of the timing of start and end of growing season along vertical and horizontal gradients in Japan. Int. J. Biometeorol. 2014, 1-8, doi:10.1007/s00484-014-0822-8.

45. Cong, N.; Piao, S.; Chen, A.; Wang, X.; Lin, X.; Chen, S.; Han, S.; Zhou, G.; Zhang, X. Spring vegetation green-up date in China inferred from SPOT NDVI data: A multiple model analysis. Agric. For. Meteorol. 2012, 165, 104-113. 
46. Tucker, C.J.; Pinzon, J.E.; Brown, M.E.; Slayback, D.A.; Pak, E.W.; Mahoney, R.; Vermote, E.F.; el Saleous, N. An extended avhrr 8-km NDVI dataset compatible with MODIS and SPOT vegetation NDVI data. Int. J. Remote Sens. 2005, 26, 4485-4498.

47. Badeck, F.W.; Bondeau, A.; Böttcher, K.; Doktor, D.; Lucht, W.; Schaber, J.; Sitch, S. Responses of spring phenology to climate change. New Phytol. 2004, 162, 295-309.

48. Piao, S.; Fang, J.; Ciais, P.; Peylin, P.; Huang, Y.; Sitch, S.; Wang, T. The carbon balance of terrestrial ecosystems in China. Nature 2009, 458, 1009-1013.

49. Che, M.; Chen, B.; Innes, J.L.; Wang, G.; Dou, X.; Zhou, T.; Zhang, H.; Yan, J.; Xu, G.; Zhao, H. Spatial and temporal variations in the end date of the vegetation growing season throughout the Qinghai-Tibetan Plateau from 1982 to 2011. Agric. For. Meteorol. 2014, 189, 81-90.

(C) 2014 by the authors; licensee MDPI, Basel, Switzerland. This article is an open access article distributed under the terms and conditions of the Creative Commons Attribution license (http://creativecommons.org/licenses/by/3.0/). 